\title{
Parental Involvement in the Arab and Jewish Educational Systems
}

\author{
Moshe Sharabi ${ }^{1}$, Gilad Cohen-Ynon ${ }^{1} \&$ Marina Soskis ${ }^{2}$ \\ ${ }^{1}$ Department of Organizational Development and Consulting, Yezreel Valley Academic College, Israel \\ ${ }^{2}$ Arlosoroff Elementary School, Haifa, Israel \\ Correspondence: Moshe Sharabi, Department of MA Studies in Organizational Development and Consulting, \\ Yezreel Valley Academic College, Emek Yezreel, 19300, Israel. E-mail: moshes@yvc.ac.il
}

Received: September 7, 2020

Accepted: October 11, 2020

Online Published: January 27, 2021

doi:10.5539/ies.v14n2p69

URL: https://doi.org/10.5539/ies.v14n2p69

\begin{abstract}
To date, no comparison has been made between the Arab and Jewish educational systems regarding parental involvement. This preliminary study examines the perceptions about parental involvement as described by the pedagogic staff and compares the two sectors (Jewish vs. Arab as two ethno-religious groups). Staff members from four elementary schools (two Jewish schools and two Arab schools) were interviewed. The findings indicate that parental involvement in the Arab sector is lower than in the Jewish sector. The Arab parents have more respect and trust towards the school, the principal, and the teachers compared to the Jewish parents. This is reflected by lower involvement of the Arab parents in comparison to the Jewish parents. While Jewish parents who volunteer for parents' associations use their status to promote their personal interest (their child's benefit) and less desire to contribute to the school, Arab parents volunteer more to help the principals and teachers to get resources from the Mayor/ Head of the municipal council and less for their own child's benefit. The depth and the type of parental involvement in the Jewish and the Arab educational systems can be explained by cultural differences, namely an individualistic Jewish society vs. a collectivistic Arab society.
\end{abstract}

Keywords: parental involvement, educational system, Israeli Arab, Israeli Jews

\section{Introduction}

Parental involvement in the education system is an important and central issue in the educational process, and this involvement has increased in Israel over the years, both in the Jewish sector (Fisher, 2010; Friedman \& Fisher, 2002) and in the Arab sector (Majadele, 2005; Zahalka, 2007). Fisher (2010) notes that many studies have been conducted on parental involvement, most of which are done in elementary schools, reflecting the prominence of parents' involvement in elementary schools. Studies on this subject have shown, among other things that parental involvement is essential and that it is of great benefit to all the stakeholders. The involvement of the parents has many positive aspects both in improving the school's functioning from an organizational and pedagogic perspective (Fisher, 2010; Goodall \& Montgomery, 2014; Vassallo, 2000) and in improving students' scholastic achievement, social success, and self-image (Caldas, Bankston, \& Carl, 2005; Friedman \& Fisher, 2002; Ryan et al., 2010; Vassallo, 2000). The involvement of parents is multidimensional, composed of a variety of behaviors, attitudes, and expectations. It is also prominent in public and scientific discourse.

This unique preliminary study in Israel, examines the intra-state perception of parental involvement among Jewish and Arab school staff. The two ethnic groups have lived side by side for more than 100 years (before and after the establishment of the Israeli state) but have different cultures. While Israeli Jewish society is closer to the individualistic pole of a continuum, Israeli Arab society is closer to the collectivistic pole. In addition to cultural differences, other sources for the differences are the historical high degree of residential, educational, and occupational segregation between the two groups. Arab society in Israel is about a fifth of the total population. They live mostly in villages and as an ethnic minority they try to keep their way of life, culture, language etc. Arabic is the language of instruction in Arab schools while Hebrew is the language of instruction in Jewish schools. Although the systems are separated, they are equal in terms of curriculum, national exams etc. Therefore, it is interesting to study the differences of parental involvement among the two ethnic groups.

Our research goals are: a) understanding the depth and type of parental involvement in the Jewish and Arab educational systems. b) learning the existing advantages and difficulties with parental involvement from the point of view of Jewish and Arab pedagogic staff. c) developing a cultural model for understanding these differences 
among the two sectors.

\section{Literature Review}

Hill et al. (2004) defined parental involvement as "parents' interactions with school and with their children to benefit their children's educational outcomes and future success" (p. 1491). This definition reflects parents' perspective but there are other school stakeholders: principals, teachers, students, the municipal council, and policy makers in the Ministry of Education. Parental involvement and family-school relations have a meaningful positive influence on children's educational outcomes and their ability to succeed in the future. It maximizes the potential of students and closes demographic gaps in achievements (Hill \& Tyson, 2009; Goodall \& Montgomery, 2014; Gonzalez et al., 2013).

A review of studies regarding parental involvement among ethnic subcultures finds that in the United States Hispanic parents have low school involvement and little impact on their children's success (Ramirez, 2003; Valencia, 2002). Another study of United States elementary schools found that Hispanic parents were more involved in the social sphere while white parents were more involved in the field of academic achievement (Ryan et al., 2010). Findings show that ethnic minority parents and low-income parents tend to be less involved in their children's education (Perez, 2001; Ryan et al., 2010; Ramirez, 2003; Valencia, 2002). Perez (2001) found that in Israel teachers' perceptions of parental involvement differ between schools and among different populations, with the most positive perception of parental involvement existing in the secular public state schools, followed by the ultra-Orthodox schools, religious public state schools, and finally in Arab state schools.

\subsection{Individualist vs. Collectivist Culture and Values}

Individualism and collectivism were widely studied over the last four decades (Hofstede, 1980, 2001, 2011; Schwartz, 2013; Triandis, 2018). Based on the literature review, the main differences between individualist and collectivist culture and values are presents in Table 1 .

Table 1. Individualist vs. Collectivist Culture*

\begin{tabular}{ll}
\hline Collectivism & Individualism \\
\hline $\begin{array}{l}\text { Social pattern based on loosely connected individuals, who see themselves } \\
\text { as being independent of the collective. }\end{array}$ & $\begin{array}{l}\text { Social pattern based on closely connected individuals, who see } \\
\text { themselves as part of a specific collective (family, tribe, } \\
\text { nation). }\end{array}$ \\
$\begin{array}{l}\text { Cand op for the self and the nuclear family; valuing the right for a private life } \\
\text { achievement; autonomy, materialism. Individualism is characterized by a }\end{array}$ & $\begin{array}{l}\text { Harmony in the internal group commitment, sociability, good } \\
\text { personal and social relations, obligation, general security, } \\
\text { tradition, unity, conservatism, dependence, conformism, } \\
\text { low power distance. }\end{array}$ \\
\hline
\end{tabular}

*Based on Hofstede (1980, 2001, 2011), Schwartz (2013), Triandis (2018), and Inglehart (1997).

\subsection{The Israeli Case}

The State of Israel was founded by Jews in 1948 and its dominant culture is Jewish and secular with a Western orientation. Yet, about one fifth of Israel's population are Arabs (or Palestinians that have Israeli citizenship) of whom 83\% are Muslims, 9\% Christians and 8\% Druze (Israel Central Bureau of Statistics, 2017). Since its establishment, Israel has undergone significant political and socioeconomic changes, and had shifted from collectivistic to more individualistic values (Sharabi, Polin, \& Yanay-Ventura, 2019). As with other Western countries, this may be attributed to several factors. Hofstede (2001) suggests that high individualism is due to rapid economic growth, a high degree of social mobility, strong development of a middle class, support of private enterprise, less traditional agriculture, modern industry, and progressive urbanization, as in Israel.

Triandis (2018) addressed the level of wealth in a given society as an important factor influencing the degree of individualism, and indeed Jewish-Israeli society has been enjoying prosperity in recent decades. Another factor addressed by Triandis (2018) is exposure to international communication networks and mass media, the influence of which is certainly felt in Israel: today, Jewish society places great emphasis on individualism, cultivating personal independence and autonomy. While granting a high degree of social permissiveness, and as part of an ongoing Americanization process, Jewish-Israeli culture has become more and more materialistic, emphasizing instrumental achievements (Harpaz, 2008; Sharabi et al., 2019).

Arabs in Israel have been partially and slowly affected by these socioeconomic changes (Kaufman, Abu Baker, \& Saar, 2012; Schnell \& Shdema, 2016). Unlike Jewish society, however, Arabs in Israel tend to be more 
conservative, emphasize tradition, the welfare and safety of the group, with a rigid hierarchy system and little autonomy - all fundamentally collectivist characteristics (Kaufman et al., 2012; Sharabi, 2018). Regarding the cultural differences between Jews and Arabs, Schwartz (2013) found that Arabs in Israel are generally connected to the "conservatism" and "hierarchy" dimensions (associated with collectivism), while Israeli Jews (similar to US society) were connected to "mastery" and "affective autonomy" dimensions (associated with individualism).

\section{Method}

Since perceptions about the magnitude of parental involvement are subjective and involve unobservable aspects that can be best elicited through cooperation with the participants, this study employed a qualitative research approach within the framework of grounded theory (Corbin \& Strauss, 2014). This framework is particularly well suited for cases in which theoretical information is lacking. It requires researchers to work closely with participants and to encourage them to describe their experiences in their own terms, and to employ an interpretive and reflective methodology to understand the findings (Charmaz, 2000).

\subsection{Participants}

The study included interviews of sixteen staff members from four elementary schools (two Jewish schools and two Arab schools). In each school, the principal, assistant principal, and teachers were interviewed. The research method was semi-structured interviews that enabled the pedagogic staff to describe how they perceived the concept of parental involvement. What are the advantages, disadvantages, and difficulties of parental involvement, as well as how to improve parental involvement and decrease negative, problematic parental intervention. The main questions all the interviewees were asked: a) describe the parental involvement in your school; b) what are the difficulties arising from parental involvement in your school?; c) how the staff and the principal are coping with negative parental involvement?

\section{Findings and Discussion}

\subsection{Parental Involvement in Jewish schools}

The teachers in the Jewish sector claim that there is a gap between the expectations of the parents from their position and the actual ability to act in their position. Teachers expect parents to cooperate. However, in practice parents often do not respect the teacher's professional skills, interfere in the teacher's work, and do not give the teacher the expected backing and respect.

"Many times we turn to the parents for a particular problem regarding their child, while the parents blame us for the source of the problem. They are not attentive, do not cooperate and many times place the sole responsibility for the child's failure on us". (Anita)

"Parents are often invited to a meeting because of their child's behavioral issues and instead of thinking together about possible courses of action, the parents blame the teachers for their children's poor behavior, conflicts arise, and [there are] even situations where there is a fall out between the teachers and the parents". (Galit)

The teaching staff indicates that the composition of parents involved and active in parent association can lead to difficulties. They indicate that in past the parents put the school's needs and its promotion as a top goal while in recent years most of the involved parents are focused on their own personal needs and interests (their child and her or his class).

"In the past there were parents with an agenda, who came to support and were committed to the school's success. In recent years, these are parents whose ability to help the school is limited and they are only interested in promoting their own child". (Dalia, principal)

According to the teachers, parents take part in the institutional leadership more because of personal interests and less to contribute to the school. Teachers feel that many parents whose children have learning and behavioral difficulties volunteer to become partners in the parental leadership to be close to the source of power (the principal) and thus gain advantages for their children

"There are a few parents who are involved out of caring, [but] most of them are involved only when it comes to their child and his study needs"; "What can delay the positive involvement of parents is the composition of the parents'association". (Ety, principal)

"They are involved in the parent association to be closer to the schools' staff so they can have an influence when there is an incident with their child or when he/she gets low grades". (Malka)

One of the main difficulties raised by the teachers is the lack of a consensus between the school staff and the parents on how the parents' involvement should take place in the school. Blurred boundaries result in 
disagreements and negative intervention.

"Involvement is good, but it should be up to a certain limit"; "We need to know where to put a line. There are many schools where parents share content delivered in classrooms. I'm not sure it's right because we do not invent the curriculum, we get it from above, from the Ministry of Education and we are obligated [to follow it]"; "parents should not interfere in my work as I do not interfere with their work".(Dalia, principal)

"Parents, especially from higher socio-economic classes, have awareness, knowledge, and sometimes you have to be very careful about things... sometimes at school despite the existence of [clear] rules and laws, parents try to break them in every way leading to collision - it is negative involvement". (Efrat)

"In recent years, we have seen a trend of negative involvement, without understanding the depth of things".

"There is no clear agreement on what involvement is. And so it is difficult to determine what the boundaries are.. negative involvement [occurs] when a parent comes with his [own] agenda and tries to compel the school". (Ela)

Another difficulty that has arisen is the impatience and intolerance that some parents show towards teachers and the school. Teachers feel that sometimes the parents discuss the problems publicly, instead of raising them with the staff beforehand.

"There is also a growing phenomenon of involving the local media without examining and clarifying the issues addressed to the media"; "I think negative involvement has increased dramatically. Moreover, this is a new trend in which a parent who does not like something, turns to the press". (Orna)

"Almost every week we find ourselves in a defensive position, in front of the spokesperson of the Ministry of Education. We have to justify why we behaved one way or another, even in simple and trivial things. The parents do not bring the problem to school, they turn to the press immediately and unilaterally". (Ety, principal)

\subsection{Parental Involvement in the Arab Schools}

Teachers in the Arab sector express dissatisfaction with the degree of parental involvement in schools, saying that despite a trend of change for the better in the field; still too few parents are involved. They feel that intensive activity is needed to get more parents involved.

"Parents still rarely get involved in school. There are still parents who do not understand that they can have an impact"; "They still do not quite understand that they can influence the education system, because of tradition, because there is not enough democracy even though we try to share the difficulties with them". (Doaa)

"Parents are not trying to get involved and have an impact within the system because of historical respect for educators and the educational system...also because it is a closed society and because of traditionalism that exists in the [Arab] sector, especially among those who comes from a low socio-economic status". (Ahmed)

Teachers often feel alone in the system in face of the student's difficulties, without the cooperation of the parents and without their involvement.

"Parents rarely get involved in anything related to their child, it makes the teacher's work difficult. There is no support from home, and the teacher copes alone”. (Doaa)

"They do not take care of their child and do not visit the school even when the child has a problem with violence". (Reina)

One of the difficulties, teachers say, is the lack of parental desire for involvement due to the lack of time or indifference. There is a great difficulty in getting parents to be active in class and/or school leadership, perhaps because parental involvement is a relatively new trend in the Arab sector. On the other hand, teachers emphasize that parents avoid coming to the school or being involved because they trust the school and respect the principal's report.

"They never had a parent's association, we convince them"; "Some of the principals invite the parents every year and out of about 400 parents, about 20 arrive, a very small number, some of the parents are very busy with their work to ensuring their basic existence ...there are many parents who are indifferent because lack of time or lack of interest". (Maison)

On the other hand, principals and teachers are not interested in real parental involvement since it will make their work more complicated. However, they explain their resistance from a pedagogical point of view.

"The parents are not from the field and therefore do not assess matters well, they do not have the criteria to assess the teacher's performance. Their assessment is not professional, but emotional and according to the child's report”. (Rassha, principal) 
"There is a lot of resistance from teachers and principals that parents will be involved in the curriculum planning and there is almost no involvement in the curriculum... Among us there have been disagreements regarding parental involvement". (Dina)

Another difficulty they say stems from the fact that most active parents see being on parent association as an opportunity to be close to political sources, municipality or the local council. From the other hand, principals encourage parents who are related by family to the mayor or the village local council head to participate in the parent association.

"Parents in the association are parents who are active primarily to be close to political sources of influence". (Suha)

"Parental involvement is mainly in the financial field and in the political field vis-à-vis the [local government] authority... there is involvement towards the institutions, the municipality, if we need more resources, they pressure”. (Rassha, principal).

"They help mainly with the council, they bring me equipment ... parents from the committee help us with families that are having difficulties." (Mahmud, principal)

The educational staff in this sector also claimed that they feel there is a change occurring. The teachers feel that parents have begun to lose their faith in the school's teachers and principals, partially because the administrative staff does not always tell the parents the real situation in their school and eventually the parents find out.

"One of the reasons for the disconnect between the school and parents is that parents once had trust in the school and today there is almost none". (Maison)

"Some principals present a situation where everything is fine and do not always tell the truth, but eventually the parents find the truth and lose trust”. (Faiza)

\section{Conclusions}

The findings indicate that parental involvement in the Arab sector is lower than in the Jewish sector. Parental involvement in the Jewish sector has changed over time and their involvement is more for personal interest (their own child's benefit) and less for making a contribution to the school. This trend is weakening the authority of teachers and the school administration. In contrast, in the Arab sector, parental involvement is much lower and more for the benefit of the school. This involvement is directed mainly by the principals to acquire resources from the Mayor/ village local council because of the parent's kinship relations (the "hamula"/extended family). Compared to the Arab sector, in the Jewish sector, teachers and principals more often use the terms "negative involvement" or "parental intervention". In both sectors, the principals and teachers express resistance towards parental involvement in pedagogic contents and curriculum. They largely view it as interference. From their point of view, parental involvement should be in activities that contribute to the social aspects of the school (social events, parties, etc.). The principal's leadership can impact teacher's attitudes regarding parental involvement. It was found that teachers demonstrated positive attitudes in schools with partnership governance; resistant and negative attitudes in schools where parents were empowered; and ambivalent attitudes in schools with professional and bureaucratic modes of governance (Addi-Raccah \& Ainhoren, 2009)

According to the educational staff (teachers and principals) in both sectors, there is an agreement that parental involvement in the school is essential, but only to a certain limit. Parental involvement strengthens the prestige of the school in the community and there are benefits when parents are involved in the school's activities. The staff agrees that there are many benefits to parental involvement in the school and this can contribute to both the school staff and the students. The involvement, they say, allows parents to deepen their knowledge of their children from a pedagogical perspective, and to understand how the school functions. Parental involvement is important for the educational advancement of the child as also mentioned in other studies (Fisher, 2010; Caldas et al., 2005; Ryan et al., 2010; Vassallo, 2000; Hill \& Tyson, 2009; Goodall \& Montgomery, 2014; Gonzalez et al., 2013). Cohen and Cohen (2001) note that parental involvement is related to their world of values regarding education. The more parents believe in education and school as a central means of a better future for their children, the more they will strive to be involved.

It seems that the depth and the type of parental involvement in the Jewish and the Arab educational systems can be explained by the cultural differences (attitudes, values, communication between parents and school staff, etc.) While Jewish society is closer to the individualistic pole of the continuum, Arab society is closer to the collectivistic pole (Kaufman et al., 2012; Sharabi, 2018; Schwartz, 2013). In the Arab society, which is traditional, collectivist, and more conservative than the Jewish society, there is a higher status to the school, the principal, and the teachers. This is reflected by higher trust in the school and concern for to the school's needs, and lower 
involvement of the parents compared to the Jewish parents.

In comparison, Jewish parents have a more individualistic orientation in which their child is in the center. They are more critical towards the school staff and more involved. Jewish parents who volunteer for parent associations use their status to benefit their child and his/ her class needs, while Arab parents help the principals and teachers get resources from the mayor/ head of the municipal council. These differences of parental involvement reflect individualist vs. collectivist orientation among the two ethnic groups (Kaufman et al., 2012; Sharabi, 2014, 2018; Schwartz, 2013).

The Arab society in Israel is changing and going through rapid modernization and democratizations processes that will lead eventually to a more individualistic society (similar to the transformation of the Israeli Jewish from collectivistic to individualistic society over the last 70 years). Therefore, we suggest executing cross sectional studies about parental involvement among the Arabs and Jews in Israel (and among minority and majority ethnicities in other countries) to examine the changes in parental involvement and the perceptions of school staff regarding parental involvement.

\section{References}

Addi-Raccah, A., \& Ainhoren, R. (2009). School governance and teachers' attitudes to parents' involvement in schools. Teaching and Teacher Education, 25(6), 805-813. https://doi.org/10.1016/j.tate.2009.01.006

Caldas, S. J., Bankston, C. L., \& Carl III, L. (2005). Forced to fail: The paradox of school desegregation. Greenwood Publishing Group.

Charmaz, K. (2000). Grounded theory: Objectivist and constructivist methods. Handbook of qualitative research (2nd ed., pp. 509-535). Thousand Oaks, CA.

Cohen, H., \& Cohen, A. (2001). The world of values of the parents of fifth graders in state and state-religious schools. In N. Masblovti, \& J. Iram (Eds.), Education for Values in Diverse Teaching Contexts (pp. 176-163). Tel Aviv: Ramot.

Corbin, J., \& Strauss, A. (2014). Basics of qualitative research: Techniques and procedures for developing grounded theory. Sage publications.

Fisher, Y. (2010). It is also possible otherwise: success stories of parent partnerships in school. Tel Aviv: Mofet Institute.

Friedman, Y., \& Fisher, Y. (2002). Identification and Awareness: Fundamentals of Parental Involvement in School Activities. Studies in the Administration and Organization of Education, 26, 33-36.

Gonzalez, L. M., Borders, L. D., Hines, E. M., Villalba, J. A., \& Henderson, A. (2013). Parental involvement in children's education: Considerations for school counselors working with Latino immigrant families. Professional School Counseling, 16(3), 185-193. https://doi.org/10.1177/2156759X1701600303

Goodall, J., \& Montgomery, C. (2014). Parental involvement to parental engagement: A continuum. Educational review, 66(4), 399-410. https://doi.org/10.1080/00131911.2013.781576

Harpaz, I. (2008). Globalization and its impact on Israel's society, economy, and labor market. VDM Publishing. Saarbrucken, Germany.

Hill, N. E., \& Tyson, D. F. (2009). Parental involvement in middle school: a meta-analytic assessment of the strategies that promote achievement. Developmental psychology, 45(3), 740. https://doi.org/10.1037/a0015362

Hill, N. E., Castellino, D. R., Lansford, J. E., Nowlin, P., Dodge, K. A., Bates, J. E., \& Pettit, G. S. (2004). Parent academic involvement as related to school behavior, achievement, and aspirations: Demographic variations $\begin{array}{lllll}\text { across adolescence. } & \text { Child }\end{array}$ https://doi.org/10.1111/j.1467-8624.2004.00753.x

Hofstede, G. (1980). Culture's Consequences: International Differences in Work-Related Values. Beverly Hills, Cal., and London: Sage.

Hofstede, G. (2001). Culture's consequences: Comparing values, behaviors, institutions and organizations across nations. Sage publications.

Hofstede, G. (2011). Dimensionalizing cultures: The Hofstede model in context. Online readings in psychology and culture, 2(1), 2307-0919. https://doi.org/10.9707/2307-0919.1014

Inglehart, R. (1997). Modernization and postmodernization: Cultural, economic, and political change in 43 
societies. Princeton, N.J.: Princeton University Press.

Israel Central Bureau of Statistics-ICBS. (2017). Statistical abstracts of Israel. Hemed, Jerusalem.

Kaufman, I., Abu-Baker, K., \& Saar, A. (2012). Arab society in Israel (Vol. 2). The Open University, Raanana, Israel.

Majadele, S. (2005). Factors influencing parental involvement in school activities in the Arab sector in Baqa al-Arabiya. Al-Qasmi, Academic College of Education in Israel.

Perez, T. (2001). Feeling of satisfaction, burnout and teachers' perception of parental involvement in their schools: A comparison between schools from different sectors (orthodox, secular, Arabic and private orthodox) (Master's dissertation, Bar-Ilan University).

Ramirez, A. F. (2003). Dismay and disappointment: Parental involvement of Latino immigrant parents. The Urban Review, 35(2), 93-110. https://doi.org/10.1023/A:1023705511946

Ryan, C. S., Casas, J. F., Kelly-Vance, L., Ryalls, B. O., \& Nero, C. (2010). Parent involvement and views of school success: The role of parents' Latino and White American cultural orientations. Psychology in the Schools, 47(4), 391-405. https://doi.org/10.1002/pits.20477

Schnell, I., \& Shdema, I. (2016). The role of peripheriality and ethnic segregation in Arabs' integration into the Israeli labor market. In Socioeconomic Inequality in Israel (pp. 207-224). Palgrave Macmillan, New York. https://doi.org/10.1057/9781137544810_10

Schwartz, S. H. (2013). Culture matters: national value cultures, sources, and consequences. In C. Y. Chiu, Y. Y. Hong, S. Shavitt, \& R. S. Wyer (Eds.), Understanding Culture: Theory, Research and Application (pp. 127-150). Psychology Press.

Sharabi, M. (2014). The Relative Centrality of Life Domains among Jews and Arabs in Israel: The Effect of Culture, Ethnicity and Demographic Variables. Community, Work and Family, 17(2), 219-236. https://doi.org/10.1080/13668803.2014.889660

Sharabi, M. (2018). Ethno-Religious Groups Work Values and Ethics: The Case of Jews, Muslims and Christians in Israel. International Review of Sociology, 28(1), 171-192. https://doi.org/10.1080/03906701.2017.1385226

Sharabi, M., Polin, B., \& Yanay-Ventura, G. (2019). The effect of social and economic transitions on the meaning of work. Employee Relations: The International Journal, 41(4), 724-739. https://doi.org/10.1108/ER-04-2018-0111

Triandis, H. C. (2018). Individualism and collectivism. Routledge. https://doi.org/10.4324/9780429499845

Valencia, R. R. (2002). "Mexican Americans don't value education!" On the basis of the myth, mythmaking, and debunking. Journal of Latinos and Education, 1(2), 81-103. https://doi.org/10.1207/S1532771XJLE0102_2

Vassallo, P. (2000). More than grades: How choice boosts parental involvement and benefits children (No. 383) (pp. 1-16). Cato Institute.

Zahalka, P. (2007). Between Traditionalism and Openness. Interior: Journal of Culture, Society and Education, $38,45-42$.

\section{Copyrights}

Copyright for this article is retained by the author(s), with first publication rights granted to the journal.

This is an open-access article distributed under the terms and conditions of the Creative Commons Attribution license (http://creativecommons.org/licenses/by/4.0/). 